\title{
SYNTHESIS OF A TWO-MASS ELECTRIC DRIVE WITH AN ASTATIC SYSTEM OF SUBORDINATE REGULATION AT THE ACTION OF VARIABLE FRICTION FORCES
}

Purpose. The solution of actual problem of active suppression of resilient electromechanical vibrations in an electric drive with the astatic system of automatic control is presented. Methodology. For research of damping properties of electrical drive according to a flow diagram from transmission functions on regulation and indignation a characteristic polynomial is got in the rationed form of parameters that takes into account the physical phenomena and sets intercommunications of parameters in the electromechanical system. As a result of it a characteristic polynomial at a successive dynamic decoupling appears separate interactive electromagnetic and mechanical subsystems. Thus, electromechanical interaction physically means complete extraction of energy of vibrations from a mechanical subsystem in electromagnetic with simultaneous transformation for minimum time. An electric drive for the case of realization of processes of electromechanical interaction is the dynamic extinguisher of vibrations. Results. The active resilient mechanical oscillation damping comes true due to optimization of dynamic inflexibility of mechanical description of electrical drive and as a result the required degree of stability is provided at minimum vibration and high exactness of working off indignations on loading. Originality. For the first time an electrical drive with the astatic system of automatic control at the action of variable forces of friction for the offered optimal parameters of dynamic inflexibility of mechanical description effectively damps vibrations. The synthesis of parameters of regulators according to correlations allowed to realize the maximum indexes of character of attenuation processes at a zero static error. Practical value. The synthesis method is approved in industrial conditions during the adjustment and modernization of the machine tool and is recommended for setting up automatic control systems for the operating and newly designed electric drives of technological machines. References 13, figures 2.

Key words: electromechanical system, damping, electric drive, interaction, regulation, speed controller, synthesis, variable friction forces.

Получил дальнейшее развитие метод синтеза электропривода с астатической системой подчиненного регулирования при действии переменных сил трения с активным демпфированием упругих механических колебаний, что достигается выбором определенного соотношения динамических параметров. Показано, что параметры в электромеханических системах находятся во взаимосвязи, а реализация расчетных соотноцений для регулятора скорости при оптимизации основана на компенсации влияния упругих сил инерционными и может быть использована для настройки систем управления технологических машин. Библ. 13, рис 2.

Ключевые слова: электромеханическая система, демпфирование, электропривод, взаимодействие, регулирование, регулятор скорости, синтез, переменные силы трения.

Introduction. The regulated automated electric drive (ED) of modern technological machines fulfills the functions of limiting dynamic loads of electrical and mechanical equipment; in theory, it provides a high static and dynamic accuracy of the reproduction of control laws and invariance to perturbations normalized rapidity $[1,2]$. However, the practical implementation of the dynamic capabilities of ED is difficult due to the influence on the processes of regulation and control of elastic mechanical links of gears, the action of variable frictional forces on the shaft of working mechanisms [3, 4]. In the low-speed mode in ED with a wide range of regulation, variable friction forces in combination with elastic mechanical oscillations are the cause of self-oscillations and loss of stability $[5,6]$.

Problem definition. In published scientific research, the results of the analysis are presented and methods for synthesizing two-mass electromechanical systems (EMS) based on various optimization criteria are proposed, as a rule, without consideration of the interaction effects of subsystems [7-9], therefore it is of interest to investigate electric drives with an astatic system of automatic regulation and minimization of vibrational components of processes under the action of variable friction forces and optimal (limiting) electromechanical interaction.
The two-mass EMS with an astatic subordinate control system is represented by the structural circuit in Fig. 1. When describing the structural circuit, a relative form of writing of parameters is used, and the control object is characterized by the following parameters: $T_{M 1}=J_{1} \omega_{H} / M_{H}$ is the mechanical time constant of the electric motor; $T_{M 2}=J_{2} \omega_{H} / M_{H}$ is the mechanical time constant of the mechanism (the second mass reduced to the motor shaft); $\Omega_{12}=\sqrt{c_{12}\left(T_{M 1}+T_{M 2}\right) / T_{M 1} T_{M 2}}$ is the frequency of free oscillations of a two-mass EMS; $c_{12}=C_{12} \omega_{H} / M_{H}$ is the coefficient of elasticity of mechanical transmission; $\beta_{C}= \pm B_{C} \omega_{H} / M_{H}$ is the coefficient of friction of the mechanical load for different parts of the characteristic; $\gamma=\left(T_{M 1}+T_{M 2}\right) / T_{M 1}$ is the coefficient of distribution of inertial masses of the motor and the mechanism.

At tuning the current (torque) loop to the maximum speed, the influence of elastic mechanical oscillations on it for the integration constant of the current loop $T_{T}<<T_{y}$ $\left(T_{y}=1 / \Omega_{12}\right)$ and $\gamma=1.01-1.5$ is considered insignificant [7] which allows the transfer function to be adopted after conversion as $W_{K T}(p) \approx 1.0$. The speed controller is proportional-integral with the transmission coefficient $K_{R}$ and the integration constant $\tau$ provides zero static error when the load $m_{C}$ changes on the shaft of the mechanism. 
Investigations of the influence of variable friction forces are performed for individual (linearized) sections of the load characteristic. Under the influence of elastic links in combination with the manifestation of «negative» viscous friction $\left(\beta_{C}<0\right)$, vibrations are excited in EMS with destabilization of the control processes and loss of stability [10]. There are also problems of stability of EMS with a doubly integrated automatic control system in the low-speed mode and with the action of friction forces on the increasing section of the load characteristic $\left(\beta_{C}>0\right)$.
The goal of the investigation is solution of the actual problem of active suppression of elastic electromechanical oscillations in EMS with an astatic system of automatic regulation. If the damping of the elastic mechanical oscillations is carried out by optimizing the dynamic stiffness of the mechanical characteristic of the ED [11], then it is possible to provide the required degree of stability with minimal EMS vibrations and high accuracy of working out the load perturbations.

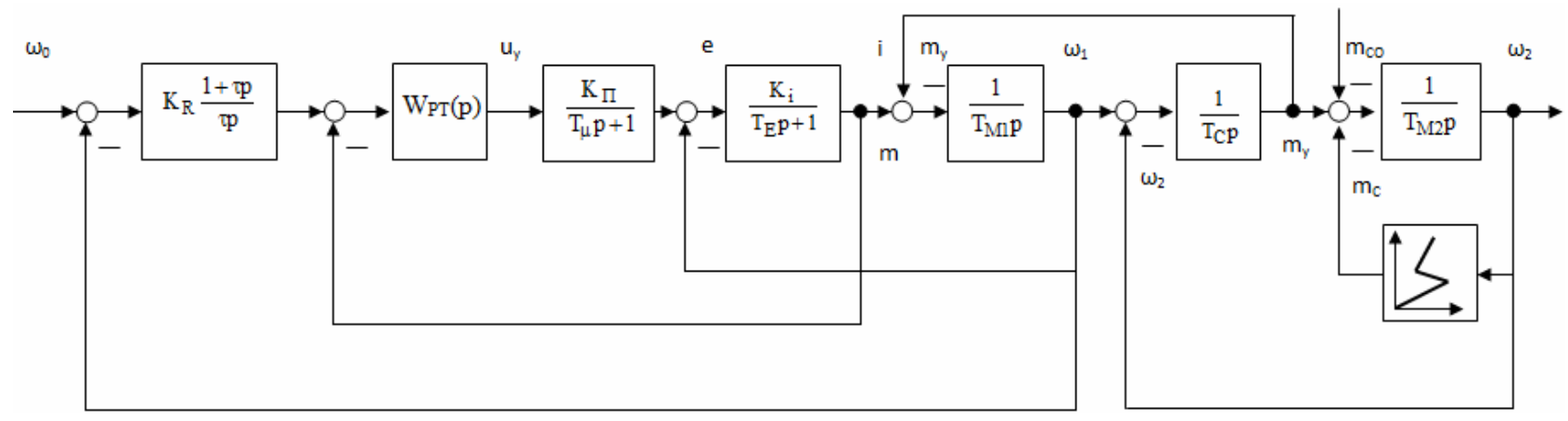

Fig. 1. Structural circuitf a two-mass electromechanical system with nonlinear mechanical loading at astatic regulation

To study the damping properties of EMS on the basis of the structural circuit, the transfer functions are obtained for the control and disturbing actions, of which, as in the source [10], the characteristic polynomial (CP) is used:

$$
\begin{aligned}
& Q(p)=\gamma T_{M 1} \tau T_{y}^{2} p^{4}+\left(\gamma K_{R} \tau T_{y}^{2}+T_{M 1} \tau T_{d}\right) p^{3}+ \\
& +\left(\gamma T_{M 1} \tau+K_{R} \tau T_{d}+\gamma K_{R} T_{y}^{2}\right) p^{2}+ \\
& +\left(K_{R} T_{d}+\left(K_{R} \pm \beta_{C}\right) \tau\right) p+K_{R} .
\end{aligned}
$$

Research materials. In CP (1), for convenience of writing and analysis, the following notations are accepted: $T_{d}= \pm \beta_{C} / c_{12}$ is time constant due to viscous friction; $T_{y}=1 / \Omega_{12}$ is the time constant of elastic vibrations.

If after the transformation of expression

$$
K_{R} \pm \beta_{C}=K_{R}\left[1 \pm \frac{\beta_{C}}{K_{R}}\right]
$$

we denote

$$
1 \pm \frac{\beta_{C}}{K_{R}}=\varepsilon
$$

then the meaning of the coefficient $\langle\varepsilon\rangle$ becomes understandable - it characterizes the additional deviation in the dynamics of the velocity of the mechanism $\omega_{2}$ under the action of the variable friction forces.

In the region of small deviations from the point of steady-state oscillation mode

$$
\begin{gathered}
\varepsilon>1 \text {, if } \beta_{C}>0, \omega<\omega_{0}, \\
\varepsilon=1 \text {, if } \beta_{C}=0, \omega=\omega_{0}, \\
0<\varepsilon<1, \text { if } \beta_{C}<0 \text { and }\left|\beta_{C}\right|<K_{R}, \omega>\omega_{0} .
\end{gathered}
$$

Then for the canonical form of the polynomial

$$
\begin{aligned}
& Q(p)=\gamma \frac{T_{M 1}}{K_{R}} \tau T_{y}^{2} p^{4}+\left(\gamma \tau T_{y}^{2}+\frac{T_{M 1}}{K_{R}} \tau T_{d}\right) p^{3}+ \\
& +\left(\gamma \frac{T_{M 1}}{K_{R}} \tau+\tau T_{d}+\gamma T_{y}^{2}\right) p^{2}+\left(T_{d}+\varepsilon \tau\right) p+1 .
\end{aligned}
$$

To analyze the active suppression of elastic vibrations with the development of destabilization processes in the case of astatic regulation in terms of CP (1) is difficult because of the many options for combining parameters and particular solutions. Therefore, we represent $\mathrm{CP}$ (3) in the normalized form taking into account generalized parameters

$$
\left.\begin{array}{l}
K_{B}=\frac{\Omega_{12}^{2}}{\Omega_{E}^{2}}=\frac{\tau T_{M 1}}{K_{R} T_{y}^{2}} ; \\
\xi_{D}=\frac{1}{2} \sqrt{\frac{\tau K_{R}}{T_{M 1}}} ; \\
\xi_{C}=\frac{T_{d}}{2 \sqrt{\gamma} T_{y}} ; \\
\gamma=\frac{T_{M 1}+T_{M 2}}{T_{M 1}} .
\end{array}\right\}
$$

The proposed form of the normalization of the polynomials of electromechanical interaction processes [11] takes into account physical phenomena and establishes the interrelations of the EMS parameters.

According to (4), $K_{B}$ is the interaction coefficient of electromagnetic and mechanical EMS subsystems; $\xi_{D}$ is the coefficient of damping of the (separate) partial electromagnetic subsystem; $\xi_{C}$ is the coefficient of damping of the (separate) partial mechanical subsystem, and

$$
\begin{gathered}
\xi_{C}>0, \beta_{C}>0, \varepsilon>1, \\
\xi_{C}=0, \beta_{C}=0, \varepsilon=1, \\
\xi_{C}<0, \beta_{C}<0, \varepsilon<1,\left|\beta_{C}\right|<K_{R} .
\end{gathered}
$$

In a joint consideration of relations (4) for $K_{B}$ and $\xi_{D}$, we obtain the formulas for the relationship between the EMS parameters of the initial structural circuit with generalized exponents 


$$
\left.\begin{array}{c}
\frac{T_{M 1}}{K_{R}}=\frac{\sqrt{K_{B}} T_{y}}{2 \xi_{D}} ; \\
\tau=2 \sqrt{K_{B}} \xi_{D} T_{y} .
\end{array}\right\}
$$

Taking the valuation form (5), we represent $\mathrm{CP}$ in the form

$$
\begin{aligned}
& Q(p)=\gamma K_{B} T_{y}^{4} p^{4}+2\left(\gamma \sqrt{K_{B}} \xi_{D}+\sqrt{\gamma} K_{B} \xi_{C}\right) T_{y}^{3} p^{3}+ \\
& +\left(\gamma\left(1+K_{B}\right)+4 \sqrt{\gamma} \sqrt{K_{B}} \xi_{D} \xi_{C}\right) T_{y}^{2} p^{2}+ \\
& +2\left(\varepsilon \sqrt{K_{B}} \xi_{D}+\sqrt{\gamma} \xi_{C}\right) T_{y} p+1 .
\end{aligned}
$$

ED at working out the speed deviation with zero static error under load action, variable friction forces and steady motion with damping of processes in the mechanical subsystem will be a dynamical vibration suppressor.

In this case, CP (6) with a successive dynamic decomposition is represented by separate interacting electromagnetic and mechanical subsystems with the description of the processes in the following form:

$$
Q(p)=\left(T_{0}^{2} p^{2}+2 \xi_{1} T_{0} p+1\right)\left(T_{0}^{2} p^{2}+2 \xi_{2} T_{0} p+1\right)=0 .
$$

The electromechanical interaction of the processes in the description in the form (7) physically means the complete extraction (retraction) of vibration energy from the mechanical subsystem to the electromagnetic one with simultaneous transformation at $\xi_{2} \rightarrow \xi_{1}$ in the minimum time. written as

The CP (7) after conversion to the standard form is

$$
\begin{aligned}
& Q(p)=T_{0}^{4} p^{4}+2\left(\xi_{1}+\xi_{2}\right) T_{0}^{3} p^{3}+\left(2+4 \xi_{1} \xi_{2}\right) T_{0}^{2} p^{2}+ \\
& +2\left(\xi_{1}+\xi_{2}\right) T_{0} p+1 .
\end{aligned}
$$

The processes in EMS under the action of the variable friction forces and the excitation of elastic mechanical vibrations which are described in the normalized form (6) will correspond to processes (8) under the condition that the coefficients of the corresponding powers of the characteristic polynomial operator are equal which gives the following system of equations:

$$
\left\{\begin{array}{l}
\gamma K_{B} T_{y}^{4}=T_{0}^{4} \\
2\left(\gamma \sqrt{K_{B}} \xi_{D}+\sqrt{\gamma} K_{B} \xi_{C}\right) T_{y}^{3}=2\left(\xi_{1}+\xi_{2}\right) T_{0}^{3} \\
\left(\gamma\left(1+K_{B}\right)+4 \sqrt{\gamma} \sqrt{K_{B}} \xi_{D} \xi_{C}\right) T_{y}^{2}=\left(2+4 \xi_{1} \xi_{2}\right) T_{0}^{2} \\
2\left(\varepsilon \sqrt{K_{B}} \xi_{D}+\sqrt{\gamma} \xi_{C}\right) T_{y}=2\left(\xi_{1}+\xi_{2}\right) T_{0} .
\end{array}\right.
$$

The system of equations (9) is solved taking into account physical considerations in a complete EMS at an optimal electromechanical coupling

$$
\xi_{1} \leq \xi_{2},
$$

where $\xi_{1}=\xi_{E}$ is the coefficient of damping of the processes of the electromagnetic subsystem in the composite EMS; $\xi_{2}=\xi_{M}$ is the coefficient of damping of the processes of the mechanical subsystem in the composite EMS.
It is known that the ED may possess the damping properties of vibrations in an elastic mechanical subsystem with viscous friction under vibrational motion of an electromagnetic subsystem [12], then in a system with destabilization $\xi_{1}<1$. And, of course, the total effect of vibration damping in the mechanical subsystem can not be higher than the damping action of the electric motor. Such a restriction allows us to accept and express, in order to simplify the transformations when solving the system (9), the following notation

$$
\xi_{C}=m \xi_{D},
$$

where $m$ is the coefficient of weight (share) of damping by friction forces (in relation to $\xi_{D}$ ); $0<m<1$ is the viscous friction at moving with a speed corresponding to the positive section of the friction characteristic; $-1<m<0$ at vibrational motion with a speed corresponding to the negative section of the friction characteristic.

The processes (7) in the electromagnetic and mechanical subsystem will be equivalent, that is, they will proceed with a limiting degree of stability and minimum oscillation in the case of $\xi_{2}=\xi_{1}$ for damping

$$
\xi_{D}=\sqrt{\frac{\gamma(1+m)^{2}-2(1-m)(\varepsilon-m)+(\varepsilon-m)^{2}}{\varepsilon^{2}(1-m)^{2}+2 m(1-m)(\varepsilon-2)(\varepsilon-m)+m^{2}(\varepsilon-m)^{2}}}
$$

when performing the following relationships for generalized indices of electromechanical interaction of subsystems

$$
K_{B}=\gamma \frac{(1-m)^{2}}{(\varepsilon-m)^{2}} ; \quad \xi_{C}=m \xi_{D}
$$

The analysis of the obtained relations (12) shows that for the limiting degree of damping - the minimum of oscillation - the coefficient of the electromechanical interaction $K_{B}$ and the damping coefficient $\xi_{D}$ are determined by the mass distribution coefficient of the inertial masses $\gamma$ and by the deflection coefficient of the speed $\varepsilon$ and coefficient of weight «m». Assuming the absence of the action of variable friction forces on the shaft of the mechanism $\varepsilon=1$ and $m=0$, the following relationships are obtained:

$$
K_{B}=\gamma ; \quad \xi_{D}=\sqrt{\gamma-1},
$$

which correspond to those given in [9] for the realization of processes in EMS with a limiting degree of electromechanical damping of elastic vibrations by an astatic automatic control system. Thus, if we perform the synthesis of the EMS parameters under astatic regulation, observing the relations (12), the processes in the dynamics will correspond to the reference one (7) and when the destabilizing factors are affected with the action of the «negative» viscous friction, the EMS will be stable for $\gamma>1,0<\varepsilon<1$ and a positive frictional viscous for $1<\gamma<5$ и $\varepsilon>1$. In the limiting case, the nature of the oscillatory damping processes in the EMS will correspond to the limiting damping with the indices:

$$
\begin{gathered}
\xi_{0}=\sqrt{\frac{\gamma(1-m)^{2}-2(\varepsilon-m)(1-m)+(\varepsilon-m)^{2}}{4(\varepsilon-m)(1-m)^{2}}+m \xi_{D}^{2}} ; \\
\xi_{E}=\xi_{M}=\xi_{0},
\end{gathered}
$$




$$
\Omega_{E}=\Omega_{M}=\Omega_{E M}=\Omega_{0} \sqrt{1-\xi_{0}^{2}},
$$

where $\xi_{0}$ is the coefficient of vibration damping in EMS; $\Omega_{0}=\frac{1}{T_{0}}=\Omega_{12} \sqrt{\frac{(\varepsilon-m)}{\gamma(1-m)}}$ is the natural frequency of undamped oscillations of a two-mass EMS in dynamics equivalent to a one-mass one.

Characteristics of the processes in ED (14), (15) with the limiting degree of damping of elastic vibrations under the action of variable friction forces are achieved by setting the current regulator according to the criterion «modular optimum», and the speed regulators of the system of subordinate regulation according to the ratios

$$
K_{R}=\frac{2 T_{M 1} \xi_{D}}{\sqrt{K_{B}} T_{y}} ; \tau=2 \sqrt{K_{B}} \xi_{D} T_{y},
$$

which are obtained from formulas (5) with subsequent substitution of optimal values of the parameters $K_{B}, \xi_{D}, \xi_{C}$ from (12).

Fig. 2 shows the oscillogram of the motor torque variation $m(t)$ for small velocity deviations at a single step change in the load for a section of the characteristic with negative friction where the graph of the transient 1 is presented for the case of tuning to a symmetric optimum with typical parameters of the automatic control system in calculations without taking into account the properties of the elastic link and variable friction forces, and the graph of the transient 2 - for the case of tuning to a minimum of oscillation with optimal parameters of the automatic control system for the section of the characteristic with a «negative» friction. ED is effectively damping vibrations. In particular, the proposed method for synthesizing the parameters of the automatic control system was tested in industrial conditions while positive results were obtained when adjusting and modernizing the machine electric drive [13].

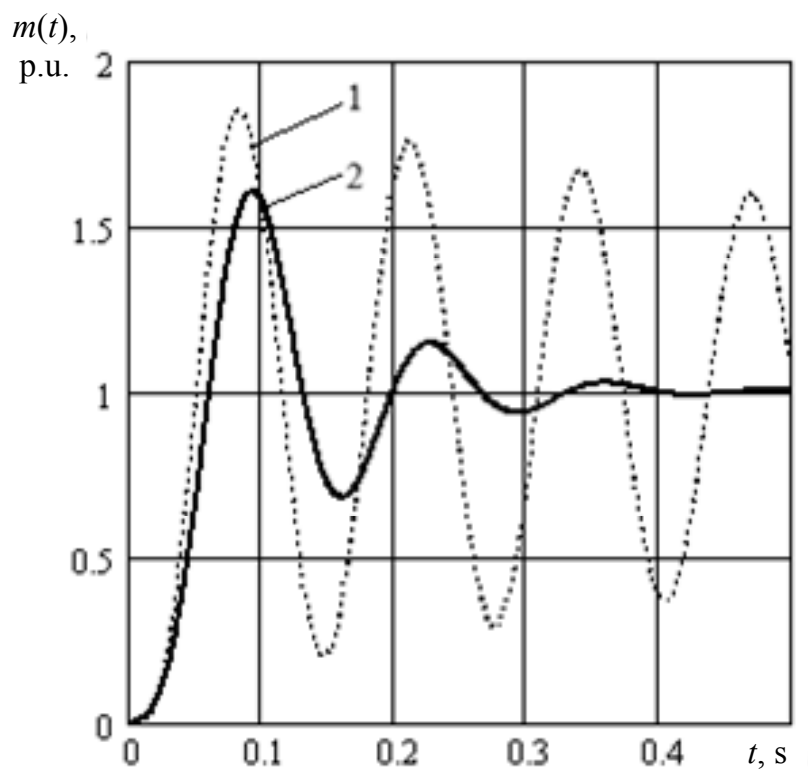

Fig. 2. Graphs of motor torque variation for small speed deviations at a single step change in load:

$1-\gamma=1.5, \Omega_{12}=62.8 \mathrm{~s}^{-1}, K_{R}=141.75, \tau=0.02 \mathrm{~s} ;$ $2-\gamma=1.5, \Omega_{12}=62.8 \mathrm{~s}^{-1}, K_{R}=65.227, \tau=0.0273 \mathrm{~s}, \xi=0.686$, $m=-0.5, \varepsilon=0.98$

\section{Conclusions.}

1. A two-mass ED with an astatic regulation system under the action of variable friction forces effectively damps the oscillations at optimizing the parameters of the regulators.

2. Synthesis of the parameters of speed regulators by the relations for the transfer coefficient $K_{R}$ and the integration constant $\tau$ makes it possible to realize the limiting indices of the nature of damped processes with zero static error.

3 . The synthesis method based on the generalized parameters $K_{B}, \xi_{D}, \xi_{C}$ and $\gamma$ satisfies the requirements of system analysis, since it takes into account the measures of mechanical, constructive, electromechanical methods of suppressing elastic mechanical vibrations.

4. The method of synthesis is recommended for practical use for control systems for ED of metallurgical and lifting-transport machines, metal-cutting machines.

\section{REFERENCES}

1. Kliuchev V.I. Teoriia elektroprivoda [Theory of the electric drive]. Moscow, Energoatomizdat Publ., 2001. 704 p. (Rus).

2. Popovich M.G., Lozins'kii O.Iu., Klepikov V.B. Elektromekhanichni sistemi avtomatichnogo keruvannia ta elektroprivodi : navch.posibnik dlia stud. vishch. navch. zakladiv, iaki navchaiut'sia za napriamom «Elektromekhanika» [Electromechanical systems of automatic control and electric drives: a manual for students of higher educational institutions in the direction of «Electromechanics»]. Kyiv, Lybid Publ., 2005. 680 p. (Ukr).

3. Andriushchenko V.A. On the stability of the traction electric drive of low speeds with unlimited increase of some of its parameters. Russian Electromechanics, 1976, no.1, pp. 100-103. (Rus).

4. Ivanchenko F.K. Mekhanika privodov tekhnologicheskikh mashin [Mechanics of drives of technological machines]. Kyiv, Vishcha shk. Publ., 1986. 152 p. (Rus).

5. Besekerskii V.A. Dinamicheskii sintez sistem avtomaticheskogo regulirovaniia [Dynamic synthesis of automatic control systems]. Moscow, Nauka Publ., 1970. 576 p. (Rus).

6. Klepikov V.B., Osichev V.B. Determination of the stability limits of an electric drive with negative viscous friction taking into account the elasticity of the kinematic chain. Electricity, 1989, no.1, pp. 36-41. (Rus).

7. Bortsov Iu.A., Sokolovskii G.G. Avtomatizirovannyi elektroprivod s uprugimi sviaziami [Automated electric drive with elastic connections]. St. Petersburg, Energoatomizdat Publ., 1992. 288 p. (Rus).

8. Burgin B.Sh. Analiz $i$ sintez dvukhmassovykh elektromekhanicheskikh sistem [Analysis and synthesis of twomass electromechanical systems]. Novosibirsk, NETI Publ., 1992. 199 p. (Rus).

9. Samuelsson O. Load modulation at two locations for damping of electromechanical oscillations in a multimachine system. Power Engineering Society Summer Meeting 2000. IEEE, 2000, vol.3, pp. 1912-1917. doi: 10.1109/pess.2000.868826.

10. Zadorozhnii N.A., Marilov N.G., Kutovoi Iu.N., Arus Mokhammed. Analysis of electromechanical drive systems with elastic mechanical connections in the regime of low speeds and slippin. Bulletin of NTU «KhPI». Series: Problems of automated electric drive. Theory and practice. Kharkov, 1997, pp. 122-123. (Rus).

11. Zadorozhnii N.A., Zadorozhniaia I.N. Synthesis of parameters of an astatic automatic control system for two-mass 
electric drives with a specified degree of stability and minimum oscillation. Bulletin of NTU «KhPI». Series: Problems of automated electric drive. Theory and practice, 2015, no.12(1121), pp. 155-159. (Rus).

12. Zadorozhnia I.M. Optimization of dynamic modes of drives of metallurgical machines with minimization of influence of elastic oscillations. Electromechanical and Energy Systems, Modeling and Optimization Methods. Conference proceedings of the 11th International conference of students and young researches. Kremenchuk, April 9-11, 2013, pp. 51-52. (Ukr).

13. Zadorozhnii N. A., Rebedak O. A., Zadorozhniaia I.N Features of the work of the feed mechanism deep machine KZH-1910 in low speed mode. Bulletin of NTU «KhPI», 2013, no.36(1009), pp. 209-210. (Rus).

Received 19.02.2018
I.N. Zadorozhniaia ${ }^{1}$, Candidate of Technical Science, Associate Professor,

N.A. Zadorozhniy ${ }^{1}$, Candidate of Technical Science, Associate Professor,

${ }^{1}$ Donbass State Engineering Academy,

72, Akademicheskaia Str., Kramatorsk, Donbass Region, 84313, Ukraine,

e-mail: zadorozhnyaya_in@ukr.net

\section{How to cite this article:}

Zadorozhniaia I.N., Zadorozhniy N.A. Synthesis of a two-mass electric drive with an astatic system of subordinate regulation at the action of variable friction forces. Electrical engineering \& electromechanics, 2018, no.3, pp. $23-27$. doi: 10.20998/2074-272X.2018.3.03. 